\title{
MI EXPERIENCIA CON LA LEY GENERAL DE EDUCACIÓN
}

\author{
My experience with the General Education Act
}

\section{Manuel de Puelles Benítez ${ }^{\alpha}$}

Mi primer contacto con la Ley General de Educación (LGE) de 1970 fue, como la de tantos otros, a través de los medios de comunicación. Yo había ingresado en 1965 en un cuerpo de funcionarios de nivel superior, el de Técnicos de la Administración civil del Estado (TAC), hoy denominado Administradores Civiles del Estado, pero mi primer destino no fue el Ministerio de Educación sino el de Industria; sin embargo, ya por aquellos años había interiorizado que la educación debía ser la palanca clave para la puesta al día de nuestro país, por lo que seguía la información sobre la reforma de la educación que Villar Palasí había emprendido como ministro de esa cartera en 1968. Recuerdo cómo me impactó el Libro Blanco sobre el estado de la educación, publicado en febrero de 1969, y cómo me pareció algo inédito en la Administración española: por vez primera se presentaba a la opinión pública un estudio riguroso que tenía como finalidad principal «describir un panorama de problemas graves y sugerir las soluciones apropiadas»,1 ofreciendo una respuesta global para todo el sistema educativo y no mediante leyes sectoriales para cada nivel al margen de cualquier marco sistémico, como se había hecho en los treinta años anteriores de ese mismo franquismo. Finalmente, cuando un periódico publicó un suplemento con la LGE me convencí entonces de que estábamos ante una ley capital, a pesar de llevar consigo el estigma de ser fruto de un régimen autoritario como era entonces el segundo franquismo, aun cuando hubiera abandonado

\footnotetext{
a Profesor Emérito, Departamento de Historia de la Educación y Educación Comparada, Facultad de Educación, Universidad Nacional de Educación a Distancia (UNED). Juan del Rosal, 28040 Madrid, España.mpuelles@edu.uned.es

1 Ministerio de Educación y Ciencia, La educación en España. Bases para una política educativa (Madrid, Ministerio de Educación y Ciencia, 1969), 7.
} 
a fortiori sus veleidades totalitarias de su primera época debido a la derrota militar de las potencias fascistas, Alemania e Italia, que tanto contribuyeron a la victoria del llamado bando nacional; por lo demás, la LGE aprobada en las Cortes orgánicas había omitido aspectos importantes de los que me ocupé después en mi libro Educación e Ideología en la España Contemporánea, aparecido en 1980, en el que vertí al respecto gran parte de la información y experiencia de los años que estuve en el MEC. ${ }^{2}$

En 1970, recién aprobada la LGE, se puso en contacto conmigo un TAC del Ministerio de Educación y Ciencia (MEC), Julio Seage, haciéndome una modesta pero interesante propuesta: presentarme a un concurso de traslados que estaba a punto de salir y cuyo objeto principal era reclutar y constituir en el MEC un grupo de funcionarios de nivel superior para participar en la ingente tarea que suponía la implantación y desarrollo de la LGE. De esta forma en poco tiempo aterrizamos en el MEC, gracias a esta política, un nutrido grupo de TACs, que trabajamos bastante coordinados desde los distintos centros directivos. Acepté, pues, encantado la propuesta y al poco tiempo me vi destinado a la Secretaría General Técnica, en la Sección de Asuntos Generales, que por esa época, si no recuerdo mal, se encargaba de los informes de las disposiciones legales del Ministerio y de todas aquellas de los distintos ministerios que se elevaban al Consejo de Ministros. Sin embargo, trabajé poco en ese cometido jurídico porque se me encargó desde el principio la preparación de un libro que ofreciera una síntesis del debate de la LGE en las Cortes españolas (orgánicas), basado en una lectura exhaustiva del Diario de Sesiones.

El proyecto que el Gobierno remitió a las Cortes se denominaba proyecto de ley general de Educación y Financiamiento de la Reforma Educativa. En el preámbulo se señalaba que la reforma global del sistema educativo requeriría un incremento notable del gasto público para hacer frente a las exigencias de la ley. A tal efecto, había dos disposiciones adicionales que para proveer de ingresos al Estado elevaban los tipos del impuesto general sobre la renta, aumentaban el impuesto sobre el tráfico de las empresas y creaban un impuesto especial sobre los beneficios

\footnotetext{
2 Manuel de Puelles Benítez, Educación e ideología en la España Contemporánea (1767-1975) (Barcelona, Labor, 1980), 412-459.
} 
de las sociedades mercantiles; a estas disposiciones le acompañaba otra que establecía el presupuesto de gastos corrientes para los diez años de implantación de la ley, valorado en pesetas constantes de 1970. Estas disposiciones, que justificaban que la ley se titulara no solo de Educación sino también de Financiamiento de la Reforma Educativa, fueron remitidas a la Comisión de Hacienda de las Cortes y a la de Presupuestos respectivamente. La ley general, en cambio, fue remitida a la Comisión de Educación para debatir más de cinco mil enmiendas presentadas, formuladas por los procuradores en Cortes.

Mi sorpresa, conforme iba leyendo el Diario de Sesiones, fue progresivamente en aumento. La Comisión de Educación, sesión tras sesión durante tres largos meses, discutió ampliamente el articulado y debatió detenidamente unas enmiendas en su mayor parte irrelevantes, pero en las cuestiones fundamentales de la ley apenas se detuvieron los procuradores de la época, y cuando lo hicieron predominó casi siempre la ambigüedad, además de que las cuestiones terminológicas, los problemas secundarios o la sintaxis del articulado casi incendiaron las pasiones de los legisladores del franquismo. En cambio, a la Comisión de Hacienda le bastó un solo día para suprimir de la ley la reforma fiscal contenida en las disposiciones adicionales segunda y tercera, alegando razones técnicas y coyunturales que encubrían la solapada oposición que dentro del establishment había suscitado la ley -recuérdese la enconada lucha interna entre los «tecnócratas» y los «azules»-; lo mismo ocurrió con la Comisión de Presupuestos, que también en un solo día malogró la financiación proyectada: aquí fue suficiente mantener las cifras presupuestarias de los diez años pero señalando que eran solamente cifras indicativas, no referidas por tanto al valor que tenía la peseta en 1970, lo que, obviamente, hubiera obligado a actualizar imperativamente, año tras año, esas cifras. De esta forma en un solo día ambas comisiones comprometieron con estas sustanciales supresiones y modificaciones la efectividad de una ley tan ambiciosa como la de 1970.

Por mi parte, presenté el trabajo dentro del plazo que se me había marcado, pero nunca más supe de su destino ni, claro es, vi publicado el libro aunque, según se me había dicho, el Ministerio tenía gran interés en su edición como un medio importante para la difusión de la LGE. Cincuenta años después no recuerdo ya como era el libro que había presentado, solo me quedó en la memoria el estupor creciente que la lectura 
del Diario de Sesiones me había ido produciendo. Como es bien sabido, la LGE se publicó en agosto de 1970 con el mismo título con que fue presentada en las Cortes: Ley General de Educación y Financiamiento de la Reforma Educativa.

Sin embargo, la ley creó una dinámica extraordinaria en el área de la escolarización, en gran parte porque supo impulsar en las familias una creciente demanda de plazas escolares, sobre todo en la enorme novedad que representaba entonces una educación general básica de ocho años de duración, obligatoria y gratuita. De esta demanda fui testigo y en cierto modo actor (en la modestia de mis posibilidades). Lo digo porque poco después del frustrado trabajo sobre el debate de la LGE, fui nombrado jefe de la flamante Sección de Programación de Efectivos de la nueva Dirección General de Personal. El cometido de esta sección era, como su nombre indica, tener a punto una programación de las necesidades de personal docente para cumplir el proyecto de escolarizar a toda la población desde los seis a los catorce año, proyecto ambicioso pero prácticamente de imposible cumplimiento, dada la escasa inversión pública de que se disponía al denegarse los recursos financieros extraordinarias por las ya referidas comisiones de Hacienda y Presupuestos; se comprometía así no solo el plan de nuevas construcciones escolares para satisfacer esa demanda sino también la urgente reforma de las antiguas escuelas, algunas en un estado físico verdaderamente deplorable.

Recuérdese a este respecto que el MEC de aquellos primeros años setenta del pasado siglo era un verdadero diplodocus, fruto desmedido de una férrea centralización de treinta años de franquismo. Todo había que solicitarlo "de Madrid», desde la más humilde escuela de aldea hasta la más imponente universidad de nueva creación. Como yo era uno de esos funcionarios que desempeñaban un papel en esa locura burocrática, tuve que hacer frente a esa explosión de la demanda. Posiblemente no se ha subrayado lo bastante el hecho de que aquellos años primeros de la LGE fueron de una constante presión popular para atender las peticiones de nuevas plazas escolares. De hecho, no había día en que no recibiera una llamada o varias de los delegados provinciales acosados por un hecho insólito en aquellos tiempos del tardofranquismo: constante concentración ante las delegaciones provinciales del MEC de padres de familia, sobre todo madres, que utilizaban todos los 
medios pacíficos para llamar la atención del representante del MEC en la provincia: caceroladas, pancartas, eslóganes, petición de que el delegado recibiera a una comisión para exponer sus demandas, etc., etc. ¿Qué hicimos entonces los que «en Madrid» recibíamos esas llamadas angustiosas de los delegados? Hay que decir que la «moderna» programación de efectivos que entonces hacíamos era, en realidad, la concesión de unos cupos a las delegaciones para contratar nuevos maestros y profesores. Y lo que pedían los delegados era justamente rebasar esos cupos, totalmente insuficientes para atender todas las peticiones familiares de escolarización. Había, pues, que autorizar al delegado a rebasar los cupos... y buscar los recursos financieros para ello. Obviamente, en la respuesta intervenían necesariamente varias unidades del MEC y, aunque siempre a la zaga de la demanda, en esos años se arbitraron, nunca mejor dicho, varios remedios excepcionales: autorización de dobles, incluso a veces triples turnos en las mismas aulas del centro docente, habilitación de naves industriales para la enseñanza, instalación de aulas prefabricadas, a veces de mala calidad, etc., escolarizando así a un considerable número de alumnos que de otra forma se hubieran quedado sin un puesto escolar. En todo caso, la década de los setenta dejó a la de los ochenta la solución de un problema verdaderamente nuevo: subsanar una deficiente escolarización mediante la construcción de nuevos centros docentes, dignos y adecuados para albergar en su seno la siempre pendiente renovación pedagógica.

Pocos años después, pasé a desempeñar la secretaria general, con nivel orgánico de Servicio, de la Dirección General de Programación e Inversiones. Seguía, pues, ligado a la problemática de la programación de la escolarización, pero de otro modo. Las secretarías generales, de novísima creación ministerial, eran órganos de asesoramiento de cada director general. Así, pues, continué lidiando con similares problemas a los descritos anteriormente, pero sin el ritmo de trabajo enloquecedor y la angustia a que estuvimos sometidos todos los que en los primeros tiempos de la implantación de la LGE tuvimos la responsabilidad, en mayor o menor grado, de la gestión de tan importante innovación de la ley, ayuna de la ayuda eficaz que podrían haber suministrado los ministerios de Hacienda y de Presidencia del Gobierno si no se hubieran suprimido las disposiciones adicionales ya referidas con anterioridad. 


\section{REFERENCIAS}

De Puelles Benítez, Manuel. Educación e ideología en la España Contemporánea (1767-1975). Barcelona, Labor, 1980.

Ministerio de Educación y Ciencia. La educación en España. Bases para una política educativa. Madrid, Ministerio de Educación y Ciencia, 1969. 